\title{
Commentary: If you cram you get SAM
}

Patrick M. McCarthy, MD, ${ }^{a}$ and Steven F. Bolling, MD

Video clip is available online.

Systolic anterior motion (SAM) after mitral valve repair can be a serious problem and is best avoided (Video 1). The anterior mitral leaflet is pulled toward the septum during systole creating mitral regurgitation and potentially causing a gradient across the left ventricular outflow tract (LVOT). Patients may be fine at rest but develop symptoms with exercise or when dehydrated. Beta-blocker medications may be used to decrease SAM, but may produce side effects. Rarely, patients do not respond to medical therapy and symptoms are so severe that they undergo a reoperation with rerepair, or valve replacement. Today we operate routinely on asymptomatic patients with the expectation of a durable long-term success. Trading asymptomatic disease for lifelong beta-blocker therapy, or symptoms with exertion, is not a good enough outcome even if the symptoms are not sufficient to warrant a second operation.

Ashikhimina and colleagues ${ }^{1}$ have a different perspective and less concern because SAM after cardiopulmonary bypass "can be managed conservatively in more than $90 \%$ of patients and persistence or progression of SAM is

From ${ }^{a}$ Bluhm Cardiovascular Institute, Division of Cardiac Surgery, Department of Surgery, Northwestern University Feinberg School of Medicine and Northwestern Medicine, Chicago, Ill; and the ${ }^{b}$ Department of Cardiac Surgery, University of Michigan, Ann Arbor, Mich.

Disclosures: Dr McCarthy has received consultant fees and royalties from Edwards Lifesciences, served on the advisory board for Abbott, and received an honorarium from Atricure. Dr Bolling has served as a consultant for Boston Scientific, W.L. Gore \& Associates, Abbott, Edwards Lifesciences, and Medtronic.

Received for publication Feb 27, 2020; revisions received Feb 27, 2020; accepted for publication Feb 27, 2020; available ahead of print March 19, 2020.

Address for reprints: Patrick M. McCarthy, MD, Bluhm Cardiovascular Institute, Northwestern University Feinberg School of Medicine, Northwestern University, 676 N Saint Clair St, Arkes Family Pavilion, Suite 730, Chicago, IL 60611 (E-mail: Patrick.McCarthy@nm.org).

J Thorac Cardiovasc Surg 2021;162:578-9

$0022-5223 / \$ 36.00$

Copyright (c) 2020 by The American Association for Thoracic Surgery

https://doi.org/10.1016/j.jtcvs.2020.02.129

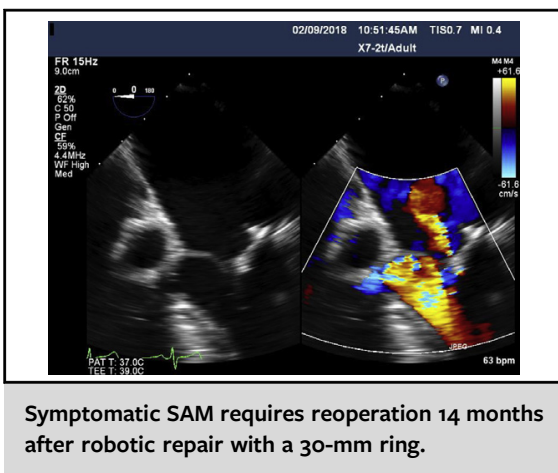

CENTRAL MESSAGE

SAM after mitral repair is not

benign, can cause symptoms and

recurrent $M R$, and can easily be

avoided with surgical planning.

rare." But the data tell a different story. The authors found SAM in 98 of 761 patients $(13 \%)$ they studied and the surgeons went back on bypass to correct the problem in $9 \%$ of those with SAM. At discharge SAM persisted in $29 \%$. Of those with persistent SAM, 28.6\% had moderate or more mitral regurgitation seen on discharge echocardiogram compared with $2.7 \%$ for those without SAM $(P=.001)$. The mean LVOT gradient was also higher (6.8 $\mathrm{mm} \mathrm{Hg}$ vs $4.8 \mathrm{~mm} \mathrm{Hg} ; P<.001)$ although "this was not associated with clinical symptoms." ${ }^{1}$ But it is hard to judge clinical symptoms a few days after surgery. There are no data on late functional class, quality of life, or the number of patients who were treated with beta-blocker medications. Although there was no difference in mitral regurgitation at final follow-up between the groups (median, 6.2 years; $P=.822$ ), all groups had higher recurrence of moderate or severe mitral regurgitation than we are used to seeing in the literature (no SAM group: 15.1\% moderate and $6.4 \%$ severe; SAM resolved at discharge group: $20.0 \%$ moderate and $7.5 \%$ severe; and persistent SAM at discharge: $17.6 \%$ moderate and $11.8 \%$ severe). For comparison, a recent report from the University of Toronto with 20 -year follow-up found $12.5 \%$ moderate or severe, and $0.6 \%$ severe $^{2}$; and a recent article from Northwestern Medicine found $9 \%$ moderate and $1.5 \%$ moderate-severe or greater at any time during 10 years of follow-up. ${ }^{3}$ Also, reoperation at the Mayo Clinic was not statistically different between groups at 5 years $(6.3 \%$ for persistent SAM, $4.3 \%$ for resolved SAM, and 3.5\% for no SAM) but was in general higher than in the Toronto experience at 20 years 


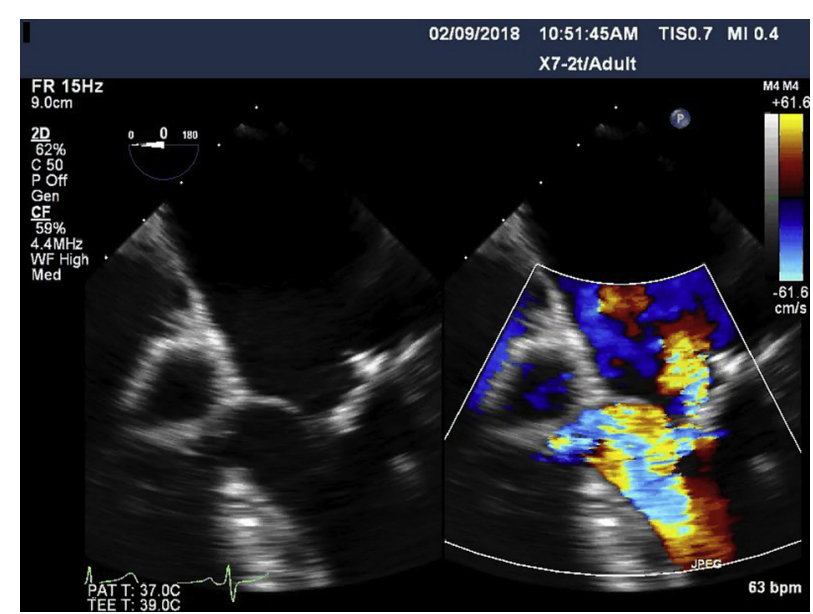

VIDEO 1. Transesophageal echo showing systolic anterior motion 13 months after robotic mitral repair using a 30-mm ring. Video available at: https://www.jtcvs.org/article/S0022-5223(20)30621-8/fulltext.

$(4.6 \%)$ and at Northwestern at 10 years $(0.5 \%)$. In the Northwestern study, SAM at discharge was only present in $0.3 \%$ of 1155 patients. In the Michigan Mitral Research group database of more than 5000 mitral surgery cases, the incidence of going back on bypass to revise suspected SAM was overall $3 \%$, and has decreased over time. Furthermore, after revision at University of Michigan Medical Center both the incidence of SAM at discharge and late reoperation for SAM was markedly diminished, approaching 0 in the latest decade.

SAM prevention begins with risk factor identification before operation and modulation of physiologic factors, such as hypercontractility and left ventricle underfilling that provoke SAM. Additionally, it is relatively straightforward to prevent SAM by using 2 simple techniques: substantially reduce the length of the elongated posterior leaflet and use a large annuloplasty ring. Both anterior and posterior leaflet lengths are elongated in degenerative mitral regurgitation. ${ }^{4,5}$ The posterior leaflet length can be shortened (to $15 \mathrm{~mm}$ or less) with resection alone or with sliding plasty or partial folding plasty, using artificial chords along with the haircut technique, or pulling the posterior leaflet into the left ventricle with short artificial chords. The coaptation zone is then moved away from the LVOT. The standard use of a $63-\mathrm{mm}$ band in $81 \%$ of patients in the Mayo Clinic study, which "corresponds to the labeled 28-mm size (inner band diameter)" 1 of most commercial bands means that pathologically elongated leaflets in degenerative mitral regurgitation have to be crammed into the space of a normal-length annulus. It may be that a single size does not fit all. For comparison, the median size degenerative repair ring at Northwestern is much larger, $34 \mathrm{~mm}$, because the pathologically elongated leaflets are better accommodated by a larger ring. ${ }^{3}$ If you cram you get SAM. There is no need to risk symptomatic SAM and a potential reoperation when we know how to avoid this problem.

\section{References}

1. Ashikhimina E, Schaff HV, Daly RC, Stulak JM, Greason KL, Michelena HI, et al. Risk factors and progression of systolic anterior motion after mitral valve repair. $J$ Thorac Cardiovasc Surg. 2021;162:567-77.

2. David TE, David CM, Tsang W, Lafreniere-Roula M, Manlhiot C. Long-term results of mitral valve repair for regurgitation due to leaflet prolapse. J Am Coll Cardiol. 2019;74:1044-53.

3. Imielski B, Malaisrie SC, Pham DT, Kruse J, Andrei A-C, Liu M. The impact of intraoperative residual mild regurgitation following repair of degenerative mitral regurgitation. J Thorac Cardiovasc Surg. November 15, 2019 [Epub ahead of print].

4. Abicht TO, Andrei AC, Kruse J, McDonald E, Li Z, McCarthy PM. A simple approach to mitral valve repair: posterior leaflet height adjustment using a partial fold of the free edge. J Thorac Cardiovasc Surg. 2014;148:2780-6.

5. Carpentier A, Adams DH, Filsoufi F. Valve exposure, intraoperative valve analysis, and reconstruction. In: Carpentier's Reconstructive Valve Surgery: From Valve Analysis to Valve Reconstruction. Maryland Heights, MO: Saunders/Elsevier; 2010:55-62. 